\title{
JUURNAL.RU
}

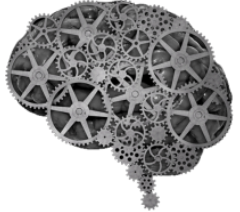

COMPANY GROUP "INTELLEKT"

\author{
Логаткина А.B. \\ Тульский государственный университет \\ Тула, Россия
}

doi: 10.18411/1j2016-3-23

\section{Возможности активной радиометрии в оценке состояния миокарда}

Учитывая высокую распространенность болезней органов кровообращения, вопросы совершенствования современных диагностических технологий, а так же повышения информативности оценки состояния миокарда у пациентов с ишемической болезнью сердца и артериальной гипертензией, в настоящее время являются высоко актуальными [1].

Повышение информативности оценки состояния внутренних органов, возможно так же за счет внедрения в клинику диагностических методов, основанных на анализе собственных полей, генерируемых организмом в процессе своей жизнедеятельности [2]. Одним из таких методов, позволяющих анализировать уровень низкоинтенсивного излучения водосодержащих сред организма, является активная радиометрия (АР) [2, 3]. АР показала свою эффективность в оценке воспалительных изменений внутренних органов, в том числе в хирургии и травматологии [4-6], а так же при оценке функционального состояния организма [7-9]. Проведенные исследования показали высокую чувствительность АР к состоянию транскапиллярного обмена воды и белка [1012], а так же к воспалительным процессам [13-20].

Цель исследования - сопоставление результатов АР миокарда и эхокардиографии у больных с артериальной гипертензией.

Материал и методы. В исследование включено 30 больных с 
верифицированным диагнозом артериальной гипертензии II-III степени сопровождавшейся развитием хронической сердечной недостаточности (XCH) IIII ФК в возрасте 40-60 лет [1]. Группу контроля составили 20 пациентов без патологии сердечно-сосудистой системы сопоставимых основной группе по полу и возрасту.

В ходе исследования всем больным проводилось эхокардиографическое исследование (ЭхоКГ) на аппарате «APOGEE-SX» с использованием датчика частотой 3,5 МГц. При ЭхоКГ из парастернального доступа определялись следующие показатели структуры и функции левого (ЛЖ) и правого желудочков (ПЖ) а так же предсердий: фракция изгнания (ФИ) ЛЖ, ударный объем (УО) ЛЖ, индекс массы миокарда (ИММ) левого желудочка, толщину задней стенки ЛЖ в систолу (ТЗСЛЖс) и диастолу (ТЗСЛЖд), конечно-диастолический (КДР) и конечно-систолический (КСР).

Волновую активность (ВА) миокарда исследовали диагностическим комплексом «Акватон» [3]. АР миокарда осуществлялось в 5 межреберье по левой парастернальной линии в течение 30 секунд [7].

Статистический анализ результатов проводили в программе Statistica 6.0. В ходе исследования анализировались такие показатели как средняя (x), медиана выборки (Ме), 25 и 75 процентили. Степень связи показателей ЭхоКГ и ВА оценивали методом линейного корреляционного анализа.

Результаты исследования. Исследованные показатели представлены в табл.1.

Результаты ЭхоКГ оценки свидетельствуют о гипертрофии и снижении насосной функции миокарда. Анализ ВА показал, что ремоделирование и снижение систолической функции сопровождается так же снижением интенсивности излучения миокарда. Линейный корреляционный анализ выявил сильную статистически значимую отрицательную связь показателей характеризующих массу (ТЗСЛЖс, ИММ) и размер полостей (КСР и КДР), а так же тесную положительная связь ФИ и ВА $[7,8]$. 
Таблица 1

Характеристика состояния миокарда обследованных больных

\begin{tabular}{|c|c|c|c|c|c|c|c|c|}
\hline Группы & \multicolumn{4}{|c|}{ Основная группа } & \multicolumn{3}{c|}{ Группа сравнения } \\
\cline { 2 - 9 } Параметры & $\boldsymbol{x}$ & $\mathbf{2 5 \%}$ & $\mathbf{M e}$ & $\mathbf{7 5 \%}$ & $\boldsymbol{x}$ & $\mathbf{2 5 \%}$ & Ме & $\mathbf{7 5 \%}$ \\
\hline ТЗСЛЖс, см. & $1,14^{*}$ & 1,0 & 1,0 & 1,3 & 0,87 & 0,8 & 0,88 & 0,95 \\
\hline ТЗСЛЖд, см. & $1,84^{*}$ & 1,4 & 1,8 & 2,4 & 1,1 & 0,93 & 1,2 & 1,4 \\
\hline КДР, см. & $6,06^{*}$ & 3,2 & 4,2 & 5,5 & 4,49 & 3,9 & 4,2 & 4,8 \\
\hline КСР, см. & $4,4^{*}$ & 5,1 & 6,0 & 6,9 & 2,84 & 2,4 & 2,9 & 3,6 \\
\hline УО, мл. & 94,2 & 68,0 & 94,0 & 116,0 & 96,5 & 87,4 & 97,1 & 105,2 \\
\hline ФИ, \% & 53 & 41 & 56 & 67 & 67 & 53 & 68 & 75 \\
\hline ИММ, г/м & $156,7^{*}$ & 98,0 & 159,0 & 206,0 & 78 & 68 & 82 & 93 \\
\hline ВА, ед. & $87,4^{*}$ & 80,0 & 86,0 & 95,0 & 102 & 95 & 105 & 117 \\
\hline
\end{tabular}

Примечание: *- статистически значимое различие с группой сравнения $(\mathrm{p}<0,05)$.

Заключение. Результаты исследования позволяют говорить о том, что у больных, имеющих низкие значения BA, формируется снижение транскапиллярного обмена в миокарде [12]. При этом АР, отражающая изменения сосудистой проницаемости, может так же использоваться для оценки состояния других внутренних органов, позволяя выявлять разнообразные патологические изменения [13-19]. 


\section{Литература:}

1. Диагностика и лечение артериальной гипертензии (Рекомендации Российского медицинского общества по артериальной гипертонии и Всероссийского научного общества кардиологов) // Системные гипертензии. 2010. №3. С. 5-27.

2. Бецкий О.В. Пионерские работы по миллиметровой электромагнитной биологии, выполненные в ИРЭ РАН // Биомедицинские технологии и радиоэлектроника. 2003. №8. С. 11-20.

3. Избранные технологии диагностики: Монография / В.М. Еськов и др.; под ред. А.А. Хадарцева, В.Г. Зилова, Н.А. Фудина. Тула: ООО РИФ «ИНФРА», 2008. 296 c.

4. Терехов И.В. Транс-резонансная функциональная топография в диагностике заболеваний органов дыхания (новый метод обработки информации): автореф. дисс. канд. мед. наук, Тула, 2007. 24 с.

5. Применение транс-резонансной функциональной топографии с целью оптимизации диагностической тактики у пациентов с подозрением на острый панкреатит и его осложнения / Лобаков А.И., Громов М.С., Дубовицкий С.А., Тер-Симонян Г.В., Терехов И.В. и др. // Хирург. 2008. № 8. C. 22-33.

6. Идентификация и дифференциация костных новообразований методом активной радиометрии / Незнамов М.Н., Зайцев В.А., Ругина Н.А., Бондарь С.С., Терехов И.В. // Вестник новых медицинских технологий. Электронное издание. 2015. Т. 9. № 2. С. 20.

7. Использование радиоволнового зондирования водосодержащих сред миокарда у больных с артериальной гипертензией / Терехов И.В., Солодухин К.А., Никифоров В.С., Ломоносов А.В. // Российский кардиологический журнал. 2013. № 5 (103). С. 40-43. 
8. Терехов И.В., Логаткина А.В., Бондарь С.С. Функциональное состояние миокарда и его связь с состоянием водосодержащих сред органов грудной клетки при инфильтративных процессах в легких // Stredoevropsky Vestnik pro Vedu a Vyzkum. 2015. T. 51. C. 3.

9. Громов М.С., Аржников В.В., Терехов И.В. Возможности оценки функционального состояния организма с помощью собственного радиоизлучения нетепловой природы // Медицинский вестник МВД. 2008. № 5 (36). C. 38-43.

10. Возможность использования активной СВЧ-радиометрии для оценки альвеолярно-капиллярной проницаемости в эксперименте / Терехов И.В., Солодухин К.А., Аржников В.В. и др. // Регионарное кровообращение и микроциркуляция. 2011. Т. 10. № 4. С. 83-86.

11. Терехов И.В., Дзюба М.А., Наджарьян Л.С. Оценка альвеолярнокапиллярных нарушений при развитии тяжелого гемодинамического отека легких у крыс и их коррекция с помощью СВЧ-излучения // Саратовский научно-медицинский журнал. 2011. Т. 7. № 2. С. 389-392.

12. Терехов И.В. Оценка сосудистой проницаемости с помощью активной радиометрии // Аспирантский вестник Поволжья. 2009. № 7-8. С. 187-190.

13. Применение метода ТРФ-топографии в диагностике воспалительных изменений нижних отделов респираторного тракта / Терехов И.В., Громов М.С., Парфенюк В.К. и др. // Саратовский научно-медицинский журнал. 2008. T. 4. № 1. C. 79-83.

14. Терехов И.В., Парфенюк В.К. Мониторинг инфильтративных процессов нижних отделов респираторного тракта у пациентов с внебольничной пневмонией методом люминесцентного анализа в радиодиапазоне // Вестник восстановительной медицины. 2009. № 3. С. 46-50.

15. Интегральная оценка воспалительного процесса у больных внебольничной пневмонией методом активной радиометрии / В.В. Аржников, В.Б. 
Лифшиц, В.К. Парфенюк, И.В. Терехов // Саратовский научномедицинский журнал. 2011. Т. 7. № 4. С. 817-822.

16. Громов М.С., Терехов И.В. Характеристика системного воспалительного ответа у больных внебольничной пневмонией в динамике при помощи активной СВЧ-радиометрии // Казанский медицинский журнал. 2010. Т. 91. № 5. С. 611-614.

17. Дифференциальная диагностика заболеваний грудной клетки с помощью транс-резонансной функциональной топографии / Терехов И.В., Петросян В.И., Громов М.С., Масляков В.В. и др. // Вестник медицинского института "РЕАВИЗ": реабилитация, врач и здоровье. 2013. № 3 (11). С. $18-26$.

18. Диагностика и мониторинг инфильтративных процессов в грудной полости с помощью люминисцентного излучения водосодержащих сред / Аржников В.В., Терехов И.В., Громов М.С. // Медицинский вестник МВД. 2009. № 2 (39). C. 40-46.

19. Технология динамической оценки воспалительного процесса с помощью активной резонансной радиометрии / Терехов И.В., Громов М.С., Петросян В.И., Бондарь С.С. и др. // Вестник новых медицинских технологий. 2010. Т. 17. № 1. С. 135-137. 